\title{
Congenital Hypogammaglobulinaemia with Steatorrhoea in Two Adult Brothers
}

\author{
GRACE E. ALLEN,* M.B. ; DAVID R. HADDEN, † M.D., M.R.C.P.ED.
}

Brit. med. F., 1964, 2, 486-490

The antibody-deficiency syndromes have been intensively studied during the 12 years following the report by Bruton (1952) that the serum of an 8-year-old boy who had suffered frequent infections in multiple systems contained no detectable gammaglobulin. He called the condition agammaglobulinaemia. Of the cases of the syndrome subsequently reported, two main clinical groups seemed to emerge (discounting the physiological fall in gammaglobulin during the first weeks of life): those secondary to other diseases, involving loss of protein or an impairment in synthesis, and an apparently primary group. This latter group has been further separated into a "congenital" form, a severe condition manifest in early childhood demonstrating X-linked recessive inheritance, and an "acquired" form, which can affect adults and children of both sexes. There are several comprehensive reviews of this knowledge (Gitlin et al., 1959 ; Soothill and Squire, 1963). The term " hypogammaglobulinaemia" is now preferred as more sensitive assays have become available.

We have studied two brothers born in 1933 and 1935 who have been subject to repeated bacterial infection from an early age, and have had steatorrhoea throughout their lives. The diagnosis of hypogammaglobulinaemia was established in 1960. The purpose of this report is to draw attention to the survival of these cases of the unmistakably " congenital " type into adult life, without specific therapy, and their clinical improvement when gammaglobulin therapy was begun. We analyse the incidence of steatorrhoea in this syndrome and its lack of response to gluten restriction. Both cases have had severe anaphylactic-like reactions to parenteral gammaglobulin therapy, of a type not previously reported. The result of studies of the X-linked blood group in the family and the occurrence of hypergammaglobulinaemia in some relatives are reported.

\section{Case 1}

An electrician born in Belfast in 1933 was reported to have been a normal healthy baby, weight $8 \mathrm{lb}$. (3,630 g.). During infancy he had feeding difficulties and diarrhoea, and did not thrive. $\mathrm{He}$ improved on weaning on to solid food, but continued to have three or four bulky loose stools daily. Throughout his life he was smaller than other boys of his age, and this became more noticeable at puberty. At age 13 his diarrhoea became worse, and the stools became pale yellow and offensive. At the age of 19 he had a markedly distended abdomen, with splaying of the lower ribs, and considerable finger-clubbing. Throughout life he had recurrent infections, with pneumonia severe enough to warrant hospital admission at ages $3,8,10,15,19$, and 26 years. Chesty colds were frequent every year and he had a chronic productive cough with yellow sputum. Recurrent frontal and ethmoidal sinusitis was associated with the chest infections. He experienced the normal childhood virus diseases, with measles and rubella at the age of 5 , pertussis at 6 , and varicella at 7 ; there were no recurrences. At age 19 he had acute gastroenteritis, but no pathogens were isolated from the stools.

He was investigated at this hospital in 1952, when the diagnosis of idiopathic steatorrhoea, with bronchiectasis and chronic sinusitis, * The Sir George E. Clark Metabolic Clinic, Royal Victoria Hospital,

†Present address: Department of Medicine, The Johns Hopkins University School of Medicine, Baltimore 5, Maryland, U.S.A. was established. Serum proteins showed a very low level of total globulins (Table I), although electrophoresis was then not available. He took a gluten-free diet for the next two years without real improvement. His general condition was gradually deteriorating though he continued at work. At all times his bacterial infections have responded rapidly to the appropriate antibiotic or chemotherapeutic agent. In 1960 serum protein electrophoresis showed hypogammaglobulinaemia: the relevant laboratory investigations throughout his life are summarized in Table I.

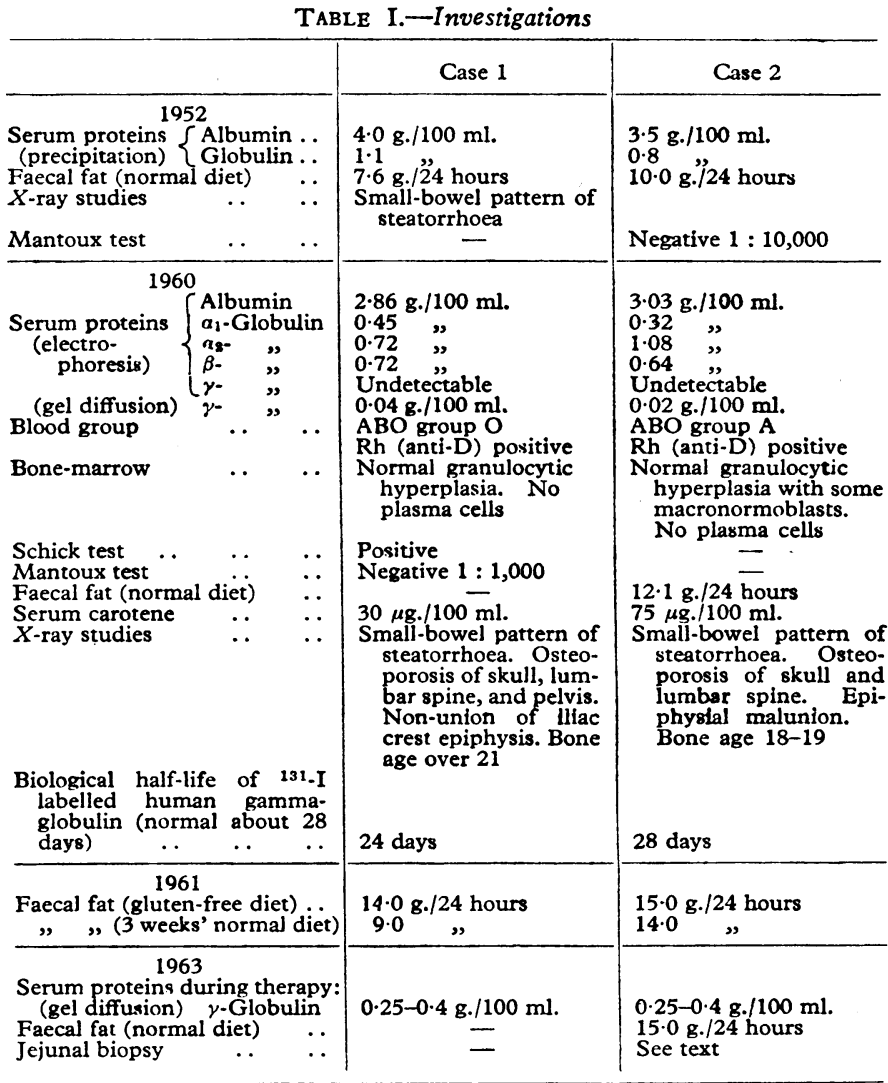

\section{Case 2}

This patient, a fitter, born in 1935 (brother of Case 1) was a normal baby who developed diarrhoea in early infancy, passing two or three loose pale bulky stools daily. He failed to thrive and was behind the normal development physically at all stages. Steatorrhoea persisted throughout childhood in a mild form, with occasional exacerbations, and was still present at his most recent admission. In early childhood a long succession of infections began. At age 5 years he had severe tonsillitis, measles, and subsequently rubella. $\mathrm{He}$ had several attacks of pneumonia, but at this stage experienced fewer than his brother. Pertussis and varicella followed in the next two years. It is of considerable interest that he had jaundice on about five occasions, but unfortunately we cannot trace records of these: the last attack was at age 15 . From age 18 he was having considerable trouble with recurrent sinusitis and other infections of the upper respiratory tract. He developed bronchiectasis, and at that time had marked abdominal distension with splaying of the lower 
ribs, and finger- and toe-clubbing. He had one episode of pyogenic arthritis of the knee-joint. All bacterial infections rapidly subsided with appropriate chemotherapy.

In 1952 the serum proteins showed a very low level of total globulin. He then took a gluten-free diet for about 18 months, and though there was a slight clinical response this was not sustained. Over the few years before his admission in 1960 his chest condition had become worse and his general health deteriorated markedly. Investigations are compared with those of his elder brother in Table I.

\section{Treatment and Response}

Since 1960 both brothers have been receiving weekly intramuscular injections of pooled human gammaglobulin (prepared by the Lister Institute, Elstree) containing $250 \mathrm{mg}$. of protein per $1.7 \mathrm{ml}$. The dose schedule was maintained at either 25 or $50 \mathrm{mg} . / \mathrm{kg}$. weekly, as indicated by the M.R.S. trial on treatment of hypogammaglobulinaemia. The improvement in physical condition was striking and can be seen in Figs. 1 and 2. Case 1 had increased from 102 to $120 \mathrm{lb}$.

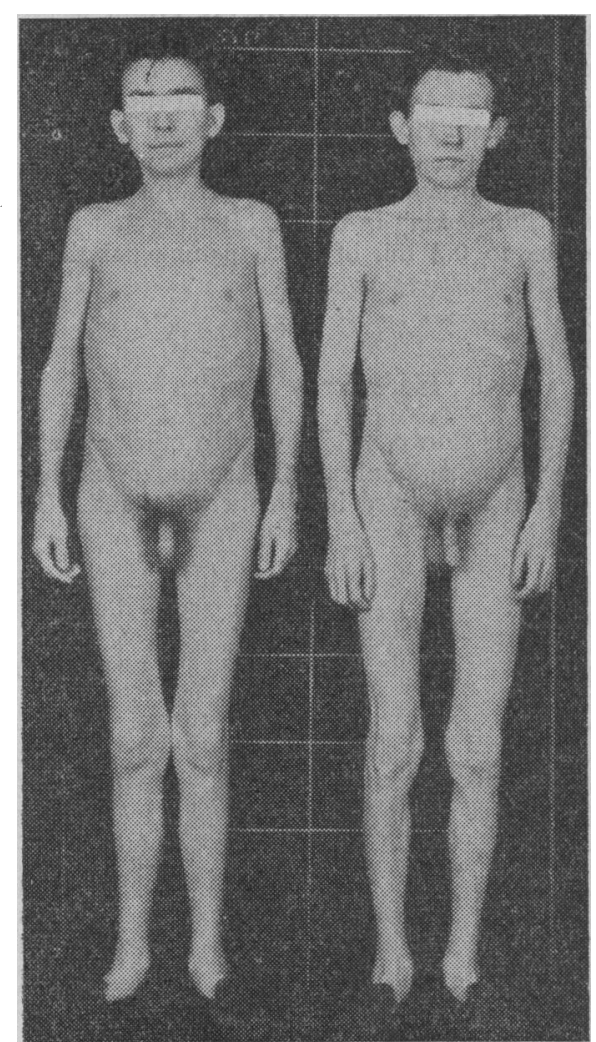

FIG. 1.-Cases 1 and 2 at ages 27 and 25, before replacement therapy with pooled human gammaglobulin.

( 46.3 to $54.4 \mathrm{~kg}$.) and Case 2 from 96 to $130 \mathrm{lb}$. (43.5 to $59 \mathrm{~kg}$.) in three years. Serum gammaglobulin levels have risen from $20 \mathrm{mg} . / 100$ $\mathrm{ml}$. (Case 2) and $40 \mathrm{mg} . / 100 \mathrm{ml}$. (Case 1) before treatment, to an average level of $250 \mathrm{mg} . / 100 \mathrm{ml}$. at present, but not exceeding 400 mg./100 ml. at any time (" normal " levels are generally between 900 and 1,400 mg./100 ml., see Table II). Both patients are now able to do a full day's work and have avoided serious affection apart from brief episodes of nasal congestion.

As both steatorrhoea and the recurrent infections were prominent when treatment was started in 1960, a gluten-free diet was reconstituted in both cases. This appeared at first to have some beneficial effect, especially when at one period Case 2 refused to keep to it, and his steatorrhoea rapidly became worse, although he was continuing with the weekly gammaglobulin injections. However, after 18 months on the diet both still had considerably elevated faecalfat excretion, and this did not rise further on stopping the glutenfree diet. The motions were still a little bulky and silvery in character, but the bowels moved only once daily. It seems probable that the clinical symptoms of both the hypogammaglobulinaemia and the steatorrhoea have responded mainly to the pooled gammaglobulin therapy, and the evidence for gluten sensitivity is slight.

Both patients have had intermittent but acute reactions to the intramuscular gammaglobulin, which we describe in detail because of their clinical and theoretical interest. They have both remained on this weekly course of injections fairly constantly until the present. After Case 2 had a second reaction he stopped his regular injections for some months, and during this time had two episodes of severe sinusitis requiring intensive treatment with antibiotics. He has subsequently improved again on regular replacement therapy.

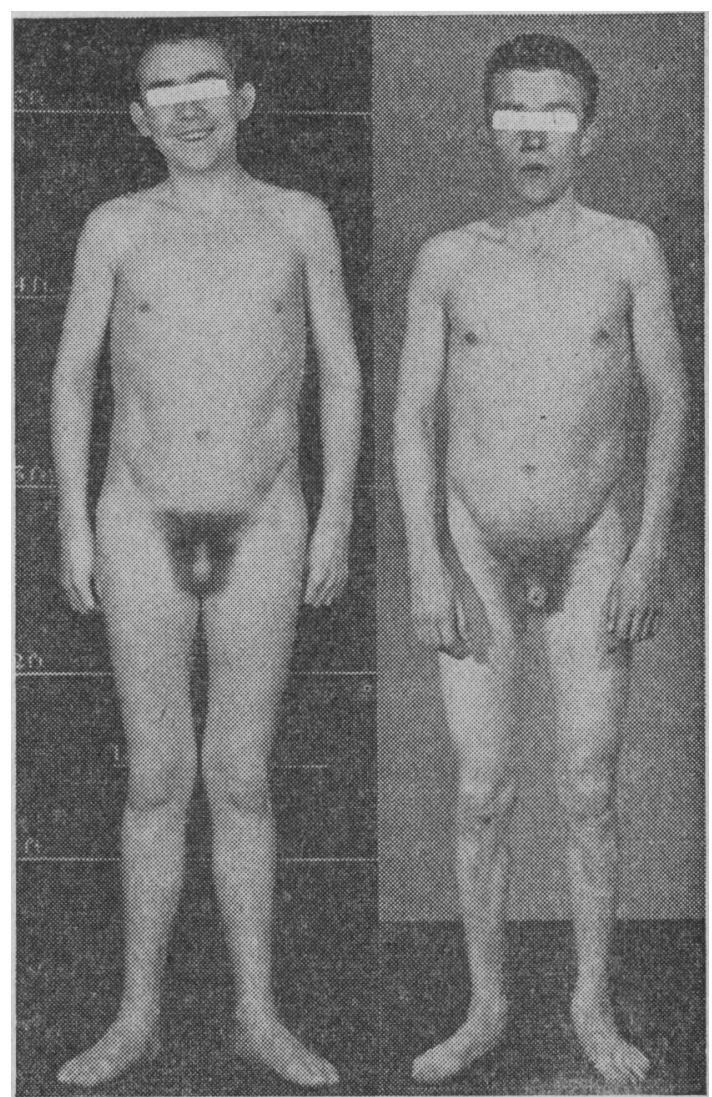

Fig. 2.-Cases 1 and 2 after 18 months' therapy.

\begin{tabular}{|c|c|c|c|c|c|c|c|}
\hline & & \multirow{2}{*}{\multicolumn{3}{|c|}{$\begin{array}{c}\text { Paper } \\
\text { Electrophoresis } \\
\text { Technique }\end{array}$}} & \multicolumn{3}{|c|}{$\begin{array}{l}\text { Gel-Diffusion-Precipitin } \\
\text { Technique }\end{array}$} \\
\hline & & & & & \multirow{3}{*}{$\begin{array}{c}7 \mathbf{S} \gamma \\
\left(7 \mathbf{S}_{\gamma_{2}}\right) \\
(\mathrm{g} . / 100 \mathrm{ml} .)\end{array}$} & \multirow{2}{*}{$\begin{array}{c}\gamma_{1} \text { Macro } \\
(19 S \gamma) \\
\left(\beta_{2} M\right)\end{array}$} & \multirow{2}{*}{$\begin{array}{c}\gamma_{1} A \\
\left(7 S_{\gamma_{1}}\right) \\
\left(\beta_{2} A\right)\end{array}$} \\
\hline & & \multirow{2}{*}{\multicolumn{3}{|c|}{$\begin{array}{c}\text { Total } \gamma \text {-Globulin } \\
\text { (On Several Occasions) } \\
(\mathrm{g} . / 100 \mathrm{ml} .)\end{array}$}} & & & \\
\hline & & & & & & \multicolumn{2}{|c|}{$\%$ of Standards } \\
\hline Case 1 & . & \multicolumn{3}{|c|}{ Undetectable } & 0.04 & $6 \%$ & $2 \%$ \\
\hline Father & $\cdots$ & $1 \cdot 80$ & $\dddot{1} \cdot 51$ & 1.65 & & & \\
\hline Mother & $\cdots$ & 2.00 & $\begin{array}{l}1.73 \\
1.08\end{array}$ & 1.76 & 1.56 & $125 \%$ & $75 \%$ \\
\hline Sister & $\cdots$ & 1.36 & $1 \cdot 98$ & - & - & - & \\
\hline \multicolumn{2}{|c|}{ "Normals" } & \multicolumn{3}{|c|}{$0.9-1.4$} & $1-1 \cdot 5$ & $115-175 \%$ & - \\
\hline
\end{tabular}

* From the Clinical Biochemistry Department, Royal Victoria Hospital, Belfag and Soothill $(1962 \mathrm{a}, 1962 \mathrm{~b})$, representing small selected groups rather than a true normal population.

\section{Steatorrhoea}

The diagnosis of steatorrhoea was apparent from the history and clinical findings. It was confirmed by the flocculent radiological pattern of barium in the small bowel, and by numerous estimations of total daily faecal fat. The levels of fat excretion were above the normal of $5 \mathrm{~g} . / 24$ hours on all occasions in both brothers, regardless of the type of diet, and particularly while each had been on a glutenfree regime for several months.

Intestinal suction biopsy in Case 2 (1963) showed marked thickening of the mucosa, with oedema of the substantia propria. Normal villi were present, but many were smaller and shortened, presumably 
as a result of the oedema. There was a moderate cellular infiltration of the substantia propria, with lymphocytes and small numbers of eosinophils. No obvious plasma cells were found, but there was a single active lymphoid follicle. The epithelium was columnar with a good brush border (Fig. 3).

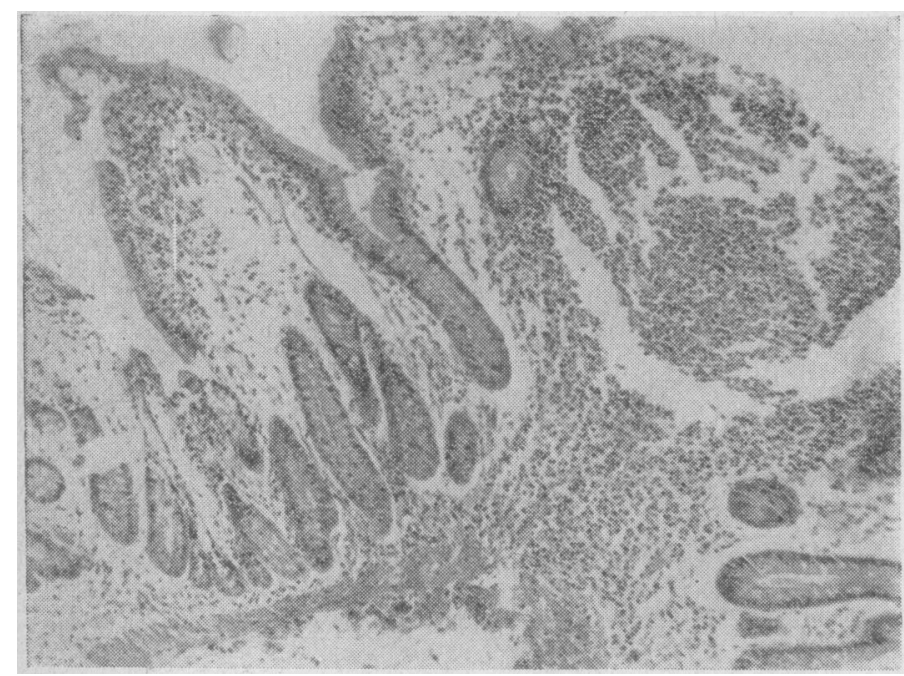

FIG. 3.-Case 2. Intestinal biopsy, showing oedema of the mucosa and an active lymphoid follicle. $(\times 127$.

\section{Reactions to Pooled Human Gammaglobulin}

\section{Case 1}

On 6 May 1960 this patient was given an intravenous infusion of ${ }^{31}$ I-labelled pooled human gammaglobulin $(250 \mathrm{mg}$. in $20 \mathrm{ml}$.). $\mathrm{He}$ complained of a slight tingling in hands and face before the injection. Immediately after it he noticed an epigastric pain and became cyanosed and weak and vomited twice. His blood-pressure was recorded at $90 / 65 \mathrm{~mm}$. $\mathrm{Hg}$, and pulse rate rose to $104 / \mathrm{m}$. The tingling persisted and he felt cold for one hour, by which time his blood-pressure had risen to $120 / 80 \mathrm{~mm}$. $\mathrm{Hg}$ and his colour had returned to normal. He had received no previous injections of gammaglobulin so far as we can ascertain, nor had he had previous blood transfusions. He admits to "feeling faint" easily, and of ten does when having an injection. He had never had an episode as severe as this before.

On 27 May 1960 he received his first therapeutic dose of 1,000 mg. of pooled human gammaglobulin intramuscularly in the buttock. He felt well immediately after the injection, and was soon allowed to go home. One and a half hours later he became acutely dyspnoeic and had several rigors at home. This episode resolved spontaneously with simple measures; it was his second known exposure to exogenous gammaglobulin. Subsequently he received weekly injections of $25 \mathrm{mg}$. of pooled human gammaglobulin per $\mathrm{kg}$. for 28 weeks without further reactions, and, apart from the usual brief period of observation after each injection, no special precautions were taken.

In January 1961 he received his 29th weekly injection. As usual he felt nervous beforehand. Immediately after he felt very sick and sweated profusely. Blood-pressure was recorded as $80 \mathrm{~mm}$. Hg systolic, and pulse rate $100 / \mathrm{min}$. There was marked laryngospasm and peripheral vasoconstriction. With elevation of the foot of the bed and warmth he felt well enough to get up two hours later. $\mathrm{He}$ has completed three years' regular therapy without further reactions.

\section{Case 2}

This patient had no reactions during his first two years' treatment. On 7 February 1963 he received his 132nd deep intramuscular injection of gammaglobulin. He had been given $19.8 \mathrm{ml}$. $(2.9 \mathrm{~g}$.). Three minutes later he suddenly became breathless and rushed to a window for fresh air: he complained of tightness in the upper chest and severe difficulty in breathing, and felt that his head would burst. He was pale, was gasping for breath and was coughing. Pulse was rapid. There was no fall in blood-pressure. Breath sounds were prolonged in expiration. He quickly improved after injections of adrenaline and an antihistamine, and went home in a few hours. $\mathrm{He}$ had no reaction to subsequent doses until the 142nd weekly injection, when after about half of the $18-\mathrm{ml}$. injection had been given he suddenly said that he was going to have a reaction again. Upper-chest tightness with coughing of mucoid sputum was followed by vomiting. He became breathless and cyanosed. During the next half-hour he became more deeply cyanosed and developed a pyrexia of $102^{\circ} \mathrm{F}$. $\left(38.9^{\circ} \mathrm{C}\right.$.) with a tachycardia of $140 / \mathrm{min}$. Blood-pressure remained normal. This reaction occurred in spite of the fact that he had just received an antihistamine intramuscularly. He rapidly responded to bed rest and intravenous hydrocortisone hemisuccinate, and his temperature fell to normal.

After these two reactions he was less well generally than for some time, being lethargic and experiencing some pain in wrists and ankles on movement. He lost weight on each occasion, but regained it fairly rapidly with continued weekly therapy.

\section{Studies of Pathogenesis of Reactions}

In 1961 gel-diffusion and tanned-red-cell studies failed to show any immunological reaction between the serum of either of the brothers and solutions of the pooled gammaglobulin with which they had been injected. In 1963 further tests for haemagglutinating antibodies (carried out by Dr. D. S. Rowe, of the Metabolic Research Unit, East Birmingham Hospital), using pooled gammaglobulin from 11 normal individuals coated on to both latex particles and red cells, revealed no reaction over a wide range of dilutions of the serum of Case 2. Direct skin-testing in Case 2 after his first reaction revealed no local reaction to $0.2 \mathrm{ml}$. of $0.5 \%$ gammaglobulin, and passive cutaneous transfer was negative.

\section{Hereditary Studies}

The family tree is shown in Fig. 4. No other cases of congenital or acquired hypogammaglobulinaemia are suggested in four generations, all of whom have lived in Northern Ireland. There was no

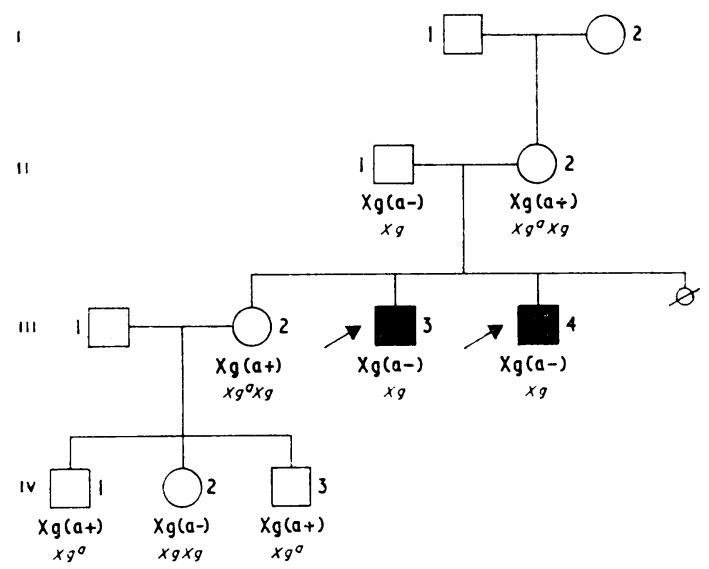

FIG. 4.-Pedigree of Family A. Affected cases in black: phenotype and presumptive genotype (italics) for the $\mathrm{Xg}$ blood group below each symbol.

consanguinity. No superficial evidence of autoimmune disease of any possible type was found in the immediate relations. The $\mathrm{Xg}^{\mathrm{a}}$ blood grouping was performed by the M.R.C. Blood Group Research Unit, London. Table II shows the serum gammaglobulin levels estimated in the close relatives by paper electrophoresis and by a gel-diffusion-precipitin technique (Soothill, 1962a). The terminology used for the immunoglobulins is that of Soothill (1962b), and other synonyms are shown. Chromosome studies failed to reveal any visible abnormality in either patient.

\section{Classification}

\section{Discussion}

The distinction between " congenital " and " acquired" forms of primary hypogammaglobulinaemia has in practice been made 
largely on the age and sex of the patient and on the level of gammaglobulin found. In general the term "congenital" has been applied to those male children with serum gammaglobulin levels below $40 \mathrm{mg}$. $/ 100 \mathrm{ml}$. who may have further evidence of a sex-linked recessive inheritance. When the diagnosis is made in adults and older children of both sexes, with somewhat higher levels of gammaglobulin (range 40-200 mg./100 ml.), the term "acquired" is used. While there is no doubt that various forms of the familial antibody deficiency syndrome exist, it seems important to recognize that classically "congenital " cases may not present and can certainly survive untreated until adult life. The terms " early" and " delayed onset" primary hypogammaglobulinaemia might be less confusing until the inheritance of the milder forms becomes more fully understood.

\section{Steatorrhoea}

In three infants reported with both primary hypogammaglobulinaemia and steatorrhoea (Bernheim et al., 1959; Garvie and Kendall, 1961) both conditions were manifest in the first year of life. The association of steatorrhoea with " acquired" or delayed onset primary hypogammaglobulinaemia is more common-estimated at $15 \%$ (Gitlin, 1962). Symptoms of steatorrhoea have generally come later than those of the protein abnormality (a mean interval of 10 years was found in a group of 11 cases reviewed from the literature). There is little support for the concept that the deficient gammaglobulin is in any way secondary to malabsorption, although other forms of steatorrhoea are often associated with low serum proteins. The normal metabolic half-life of gammaglobulin here reported, as found by Bruton (1952) and Martin et al. (1956), shows that there is no abnormality in the breakdown or elimination of this protein.

There have been several reports of temporary clinical response to a gluten-free regime in the syndrome (Bernheim et al., 1959 ; Swift, 1962 ; Roget et al., 1962), but in no case has a lasting remission been shown. The persistently raised faecal fat in both of the present cases, and the normal mucosal villi in Case 2, seem to exclude gluten sensitivity from the pathogenesis of the steatorrhoea. There is at present no obvious relation between the malabsorption and the serum protein abnormality. It is of interest that steatorrhoea was also present in the case of analbuminaemia reported by Montgomery et al. (1962).

\section{Reactions}

It is possible for the reactions reported to have been merely severe episodes of vasovagal syncope, but it is difficult to reconcile their alarming clinical presentation with this explanation. Although patients with the antibody-deficiency syndrome in general fail to respond normally to an antigen by antibody formation, some forms of allergy are known to occur (Soothill and Squire, 1963). Urticaria has followed penicillin injection, and rarely immediate skin-test reactions have been found, even in the severely affected sex-linked recessive male (Gitlin et al., 1959). Reactions to exogenous gammaglobulin have been noted to occur in normal children with measles, especially after intravenous injection (Wilson and Miles, 1955), but reactions of any sort have been very unusual among the patients in the British series of hypogammaglobulinaemia (now more than 100 in number) treated by weekly intramuscular injections for an average duration of three years (J. R. Squire, personal communication).

The possibility exists that the reactions in these brothers may be determined by an unidentified genetic mechanism against the gammaglobulin of foreign allotypes. There was no evidence in either of our cases of the excessive breakdown of gammaglobulin found in one patient by Squire (1960), and gel-diffusion and tanned-red-cell inımunological studies failed to reveal any inter- action between the serum of either patient and the batch of gammaglobulin which they were receiving. In spite of the negative skin tests we still consider, on account of their clinical severity, that these reactions have been of the anaphylactic or immediate-hypersensitivity type, but we are continuing the course of intramuscular injections. The grossly abnormal immune mechanism in these patients may account for the failure of the standard immunological procedures to reveal evidence of sensitivity. The possibility exists that the intermittent nature of the reactions is due to occasional injection direct into a muscle vein, and the typical reaction in one case to a known intravenous dose tends to support this view. It is suggested that the injection should be given with care to try to prevent this occurrence, but it is apparent that replacement therapy will have to be lifelong.

\section{Genetic Applications}

There is evidence that the "congenital" form of hypogammaglobulinaemia is determined by the segregation of a single recessive gene carried on the $\mathrm{X}$ chromosome. In support of this, virtually all familial studies reported show only affected male cases, and in no instance has the mother of an affected case manifested the full syndrome (Diamant et al., 1961). In most conditions due to a sex-linked recessive gene the rarer homozygous female is more severely affected, and frequently the condition is lethal. Several cases of "congenital" hypogammaglobulinaemia have been reported in females. That of Sanford et al. (1954), though clinically of a mild type, had a very low serum gammaglobulin level $(25 \mathrm{mg} . / 100 \mathrm{ml}$.). Bernheim et al. (1959) described the cases of a more severely affected female infant who died at age 14 months. Both of these cases had steatorrhoea. However, of nine female cases in children in the British series (who had a significantly higher mortality than the male cases), none had an affected relative, whereas there were seven male familial relationships in 41 cases (Squire, 1962). While the general incidence of female cases remains too high for a simple homozygous inheritance, it is possible that a proportion may represent this state.

There are two possible approaches to determine the heterozygous carrier state: by seeking for a biochemical or an anatomical abnormality, or by trying to find some other marker gene closely linked to the hypogammaglobulinaemia gene.

It has been suggested that those who are heterozygous for the gene may have hypergammaglobulinaemia. Young et al. (1955), Citron (1957), and Zelman and Lewin (1958) reported high levels of gammaglobulin in relatives of patients with "acquired" hypogammaglobulinaemia. Fudenberg et al. (1962) confirmed this finding, and reported increased levels of gammaglobulin in two out of seven families of patients with the "acquired" syndrome, and five out of 15 families of patients with the "congenital" syndrome. (They also noted variable changes in the $\gamma_{1} \mathrm{~A}$ and $\gamma_{1} \mathrm{M}$ fractions in the families of both types, and presented one kindred showing both acquired and congenital forms of the syndrome.) The occurrence of abnormal gammaglobulin levels in both male and female members of the present family and in those referred to suggest that this is not a sufficiently discrete abnormality to determine the heterozygous female.

The X-linked blood-group factor described by Mann et al. (1962) initially appeared to be closely linked to the hypogammaglobulinaemia gene, and the present family was one that contributed to this appearance. However, subsequent tests on other families have made close linkage seem unlikely, and it is at present uncertain whether the two loci are even within measurable distance of each other (Sanger and Race, 1963). If the two genes ultimately prove to be within measurable distance of each other, this would confirm these cases of hypogammaglobulinaemia as due to an X-borne character; if they prove not to be so related it would not necessarily call in question 
the presence of the hypogammaglobulinaemia gene on the $\mathrm{X}$ chromosome. The $\mathrm{X}$ is a long chromosome, with about 150 cross-over units, and linkage cannot be detected between genes approaching 50 cross-over units apart. The appearance of close linkage must probably be understood as a matter of chance, but this family can nevertheless be used as an illustration of how informative a real close linkage with a marker gene could be (Fig. 4). II 2 is heterozygous $X g^{a} X g$, for she is $X g(a+)$ and has $\mathrm{Xg}(\mathrm{a}-)$ children. To her two sons, III 3 and III 4 , she has given $X g$ gene and her hypogammaglobulinaemia gene; but to her daughter, III 2, she has given her $X g^{a}$ gene and, barring crossing over, a gene not determining hypogammaglobulinaemia. III 2 should therefore not be a carrier: that she appears not to be, by having two normal sons, is probably a matter of chance; for the close linkage invoked in this demonstration, we must repeat, in all probability does not exist.

\section{Summary}

Two adult brothers, aged 25 and 27 , were found to have "congenital" hypogammaglobulinaemia associated with steatorrhoea. Their clinical state has responded to parenteral gammaglobulin replacement, but steatorrhoea persists in mild degree and is not responsive to a gluten-free regime.

Both brothers have had severe intermittent anaphylactic-like reactions to the injected gammaglobulin.

Members of the immediate family were found to have hypergammaglobulinaemia.

The classification of these cases is discussed, and the incidence of steatorrhoea in hypogammaglobulinaemia reviewed. A genetic model of a possible inheritance pattern using the $\mathrm{Xg}$ blood-group system is constructed.

We wish to thank Dr. D. A. D. Montgomery for his permission and encouragement to publish these cases. Professor J. R. Squire and Dr. J. F. Soothill, of the Department of Experimental Pathology, University of Birmingham, have been responsible for the supply of gammaglobulin and the estimation of serum globulins by immunological methods, and we are grateful for their helpful criticism. Dr. R. R. Race, M.R.C. Blood Group Research Institute, London, performed the $\mathrm{Xg}^{\mathrm{a}}$ analysis, and we are grateful for his permission to publish these results. Dr. Peter Froggatt aided in the genetic analysis.

\section{REFERENCES}

Bernheim, M., Creyssel, R., Gilly, R., and Fournier, R. (1959). Pédiatrie, 14, 881 .

Bruton, O. C. (1952). Pediatrics, 9, 722.

Citron, K. M. (1957). Brit. med. F., 1, 1148.

Diamant, M., Kallos, P., and Rubensohn, G. (1961). Int. Arch. Aliergy, 19, 193 .

Fudenberg, H., German, J. L., and Kunkel, H. G. (1962). Arthr. and Rheum., 5, 565 .

Garvie, J. M., and Kendall, A. C. (1961). Brit. med. 7., 1, 548.

Gitlin, D. (1962). Disease-a-Month, May, pp. 1-40.

- Janeway, C. A., Apt, L., and Craig, J. M. (1959). In Cellular and Humoral Aspects of the Hypersensitive States, edited by H.S. Lawrence, p. 375. Hoeber-Harper, New York.

Mann, J. D., Cahan, A., Gelb, A. G., Fisher, N., Hamper, J., Tippett, P., Sanger, R., and Race, R. R. (1962). Lancet, 1, 8 .

Martin, C. M., Gordon, R. S., and McCullough, N. B. (1956). New Engl. F. Med., 254, 449.

Montgomery, D. A. D., Neill, D. W., and Dowdle, E. B. D. (1962). Clin. Sci., 22, 141 .

Roget, J., Beaudoing, A., Gilbert, Y., and Jobert, J. (1962). Pédiatrie, $17,433$.

Sanford, J. P., Favour, C. B., and Tribeman, M. S. (1954). New Engl. f. Med., $250,1027$.

Sanger, R., and Race, R. R. (1963). Lancet, 1, 859.

Soothill, J. F. (1962a). 7. Lab. clin. Med., 59, 859.

- (1962b). Clin. Sci., 23, 27.

and Squire, J. R. (1963). In Clinical Aspects of Immunology, edited by P. G. H. Gell and R. R. A. Coombs, p. 288. Blackwell, Oxford.

Squire, J. R. (1960). Acta haemat. (Basel), 24, 99.

Swift, P. N. (1962). Postgrad. med. . 55, 38, 633

Wilson, G. S., and Miles, A. A. (editors) (1955). Topley and Wilson's Principles of Bacteriology and Immunity, 4th ed., p. 2201. Arnold, London.

Young, I. I., Wolfson, W. Q., and Cohn, C. (1955). Amer. F. Med., 19, 222.

Zelman, S., and Lewin, H. (1958). Ibid., 25, 150.

\section{Preliminary Communications}

\section{Drug Assays on Organ Cultures of Biopsies from Human Tumours}

\author{
Brit. med. F., 1964, 2, 490-491
}

In previous communications (Ambrose, Andrews, Easty, Field, and Wylie, 1962 ; Easty and Wylie, 1963) a method was described for the preparation of monolayer tissue cultures from human biopsy specimens. The method was applied to the quantitative analysis of the effect of chemotherapeutic agents on human tumour specimens. Monolayer cultures have distinct advantages for studying direct effects on individual cells, but it has been known for some time that organ cultures provide conditions which resemble in vivo conditions more closely. Fell and Mellanby (1953) described effects due to vitamin A in organ culture which resemble in vivo effects. Lasnitzki (1951) described morphological changes in the presence of carcinogens, and Algard (1961) observed a response to hormones in organ culture. We have therefore developed a simple organ-culture method for the study of the response of human tumours to potential anti-tumour agents, antisera, hormones, etc.

Lens paper (Green 105) is treated with a solution of watersoluble silicone $\left(10^{-3} \mathrm{M}\right.$ Drisil supplied by Hopkins and
Williams) after washing three times with ether and twelve times with distilled water. Previous to silicone treatment small holes $1 \mathrm{~mm}$. in diameter or less may be punched in the paper, using the ground end of a hypodermic needle. A medium containing Burroughs Wellcome Eagles HeLa medium with added penicillin, insulin, $p$-aminobenzoic acid, glucose, biotin, and ascorbic acid with $10 \%$ Burroughs Wellcome calf serum is used for culture. $5 \mathrm{ml}$. of medium is placed in a disposable plastic dish. Siliconed paper is floated on the medium and a small square of unsiliconed paper placed over the hole. Fragments of biopsy tissue are cut to a size of $1-2 \mathrm{c.mm}$. and placed on the squares of paper (see Diagram). In some cases the perforation in the siliconed paper may be less than $1 \mathrm{~mm}$. in diameter or may be omitted altogether, provided that the upper surface of the paper is wetted with a drop of medium. Conditions should be arranged so that the specimens are just moist with medium. An adequate gas exchange is essential for success in organ culture (Trowell, 1959). The plastic dishes are placed in a desiccator, Trowell chamber, or plastic box. We have used a picnic box with stopcocks sealed on the lid for gassing. The lid is sealed with silicone grease. A gas mixture containing $5 \% \mathrm{CO}_{2}$ in air is passed through the apparatus.

To obtain useful data with potential anti-tumour agents it is necessary to measure cell growth or synthesis. In organ culture it is not easy to count cell numbers. We have therefore 